ECOLOGY AND SOCIETY

Home | Archives | About | Login | Submissions | Notify | Contact | Search

ES HOME > VOL. 3, NO. 1 > ART. 13

Copyright (C) 1999 by The Resilience Alliance*

Correct format for citing this article:

Whiteman, G. 1999. Sustainability for the planet: a marketing perspective. Conservation Ecology 3(1): 13. [online] URL: http://www.consecol.org/vol3/iss1/art13/

\title{
Perspective
}

\section{Sustainability for the Planet: A Marketing Perspective}

\section{Gail Whiteman}

\section{Queen's University}

- Abstract

- Introduction

- Marketing and the Climate Change Debate

- Marketing For Social and Environmental Change

- Marketing and the Scientific Community

- Enviro-marketers: Whos Out There Marketing Sustainability? What Can We Learn from Them?

- Marketing Adaptive Management: a Call to Action

- Conclusion

O Endnotes

- Responses to this Article

- Acknowledgments

- Literature Cited

\section{ABSTRACT}

This perspective presents a case for environmental scientists to mobilize their communication efforts and to develop a systematic approach to marketing scientific knowledge to a range of key target audiences. Examples of environmental marketing are presented, and a call to action is presented in the spirit of discussion.

KEY WORDS: marketing sustainability, perspective.

Published June 30, 1999.

\section{INTRODUCTION}

Human behavior is influenced by a variety of communication media. However, mass marketing tools (such as advertising, public relations, and sales promotions) have become increasingly fundamental to our consumption-based culture (Leiss et al. 1990). Advertising, in particular, has evolved into a privileged form of discourse (Leiss et al. 1990): ads are everywhere. As a practitioner of consumer packaged goods marketing, I spent long hours developing and executing detailed marketing plans for such ignoble products as Dentyne chewing gum. As a researcher in marketing, I have studied how marketing vehicles such as advertising can create, influence and change target audience attitudes, beliefs, and perceptions. In a nutshell, marketing works. That's why corporations use it. A more interesting question is, how can scientists use it too?

Within the global economy, marketing is a sophisticated and powerful tool used by companies to increase consumption, gain competitive advantage, and influence external regulatory bodies. Although this is true for many 
products, it is also increasingly true in the marketplace of ideas. As noted in the Boreal Forest Workshop (October 1997), companies and policy makers have increasingly turned to the deployment of "spin doctors" (propagandists, public relations experts, and marketers) to effectively project their message and market their side of the environmental debate (see also Chapin and Whiteman 1998). By doing so, the messages of others (e.g., those of the scientific experts), can become overshadowed or possibly manipulated.

This commentary argues for mobilization of marketing efforts among environmental scientists and academics. That is, in addition to our scientific research, we need to actively engage in systematic marketing campaigns. As researchers who are struggling to address the sustainability of the planet, it is not sufficient that we generate useful knowledge. We also have an obligation to convey that knowledge, in the most effective manner, to specified target audiences. This is even more critical in situations in which corporations and other interest groups are actively marketing less sustainable alternatives. The rhetoric surrounding the climate change debate is a case in point.

\section{MARKETING AND THE CLIMATE CHANGE DEBATE}

Leading up to the Kyoto Conference, the issue of climate change was hotly debated. In particular, the Global Climate Coalition (GCC), a powerful coalition of corporations and private sector associations, actively engaged in marketing activities to undermine the proposed Kyoto Agreement within the United States. In general, such campaigns attempted to influence public attitudes by using fear and discrediting the ability of scientists to speak in favor of the Kyoto agreement by calling for scientific "certainty" before regulatory action.

During this debate, the Global Climate Information Project (GCIP), a group funded by the GCC and others, launched a $\$ 13$ million (U.S. dollars) national advertising campaign in 1997 and again in 1998. The objective of the marketing campaign was to reduce public support for Kyoto and to further private sector interests. The ads made a variety of anti-Kyoto claims such as "It's not global and it won't work." The campaign also used fear-based tactics to reduce public support by suggesting that "Americans will pay the price... 50 cents more for every gallon of gasoline." An underlying theme of GCIP's approach was to convey the idea that until scientific "certainty" about climate change was reached, there should be no international regulatory action. Overall, the GCIP credits its marketing campaign with "energizing and shaping the public debate regarding climate change leading up to the Kyoto Conference." In addition, the Competitive Enterprise Institute (CEI), another pro-market public policy group, launched a series of radio ads along similar anti-Kyoto lines .

Although many scientists may have disagreed with the content of GCIP or CEI's marketing approach (particularly about the use of uncertainty to stall action), the mass communication of scientific perspectives was largely dependent upon external sources, such as the media and nongovernmental organizations (NGOs) [1]. Although potentially useful, such an indirect educational approach abdicates control over the effective reach of key scientific insights. Basically, this approach to communication is risky; compared to the heavily financed and fear-inducing messages of the private sector campaigns, the scientific voice may be lost, discredited, or manipulated, and the implementation of science-based environmental regulation may be stalled. In the future, scientists may wish to develop their own social marketing campaigns to more effectively compete in the marketplace of ideas.

\section{MARKETING FOR SOCIAL AND ENVIRONMENTAL CHANGE}

Social marketing (Andreasen 1995, Kotler and Armstrong 1995) encompasses the strategic design, implementation, and control of programs that seek to increase the acceptability of a social or environmental idea, cause, or practice among members of a target audience and, ultimately, to change the behavior of key target audiences. Social marketing differs from commercial marketing in two important ways: (a) benefits are not for the organization, but for "society" as a whole; and (b) the focus is on changing high-involvement behavior, i.e., changing behavior that is entrenched and that involves considerable risk-taking and/or incurs significant costs (Andreasen 1995). Unlike the marketing of consumer packaged goods, the marketing of scientific ideas may be complex: concepts may not be straightforward and behavior change may be difficult.

Consequently, a shift to sustainable corporate and consumer behavior can be seen as a high-involvement choice, one that will require sustained marketing effort over the long run.

Although different in goal and level of complexity, social marketing shares the same fundamentals as the marketing of consumer packaged goods:

1. identify clear marketing objectives, possibly using a pilot project as a test case;

2. identify key target audiences and gather pertinent information (e.g., current attitudes, expectations, behavior);

3. develop marketing strategies to communicate and influence target audience;

4. identify/create impactful communication vehicles;

5. execute plan; 
6. measure marketing impact (e.g., How many people were effectively reached? How have attitudes, expectations or behavior changed?).

Successful marketing takes time, effort, and often money. A key constraint experienced by noncommercial ventures is a lack of funding. Without funding, many social marketers feel that the battle is over before it starts. Even in the corporate world, we often felt financial pressures, particularly with smaller brands. But that is where marketing creativity comes in, using small, finite resources to gain maximum punch. The private sector calls this "guerrilla" marketing (Kotler and Turner 1993: 416), which "consists of waging small, intermittent attacks on different territories of the opponent, with the aim of ... eventually securing permanent footholds." Furthermore, guerrilla attacks use both conventional and unconventional communication approaches (see Enviro-marketers). The emergence of the electronic journal Conservation Ecology as a low-cost communication vehicle is an example of this technique. Other guerrilla techniques need to be explored.

\section{MARKETING AND THE SCIENTIFIC COMMUNITY}

At a general level, some scientists clearly understand the need to effectively communicate environmental messages. For example, the Draft Case Statement of Science and Policy Partnership for Sustainability, developed by C. S. Holling and others (The Resilience Network March 1997: 19), states that: "The Science and Policy Partnership will build a multilayered system of communication to achieve its mission." Furthermore (The Resilience Network March 1997: 3), "The aim is to facilitate the creation of a community of the highest level policy makers and scientists who, through augmented and directed communications efforts, maximize scientific findings and policy opportunities that can, in fact, overcome existing barriers of perspective, culture, geography and time."

However, these communication goals have yet to become operationalized into distinct marketing plans. Consequently, there is a need for scientists, as individuals or as groups, to develop a variety of marketing strategies, to clearly identify key target audiences, and to learn how to execute effective marketing campaigns.

The good news is that we have already started the journey. Currently, there are various electronic journals that wish to convey scientific information (the online journal Conservation Ecology is a good example) as well as the continual use of person-to-person networking. Electronic communication is a key component of many directmarketing plans. Scientific networking with external stakeholders such as policy makers is an example of relationship marketing, a strategy that focuses on attracting and maintaining a relationship with a specified target segment. These vehicles have, and will continue to be, utilized by the academic community. However, Conservation Ecology is but one example of one type of vehicle for communication. It is both innovative and potentially far-reaching within certain audiences such as academia. Yet, it is unlikely that one vehicle can reach all audiences in an effective manner. We have to utilize more than one type of communication vehicle.

Each target audience has its own information requirements, encompassing not just the type of information needed, but also the manner in which that information is communicated; i.e., the tone and content of the message and the vehicle used to convey it. Scientists have already appreciated the need "to distill these [scientific] discussions into more effective presentations to the public. We need to begin using concepts with which the public are familiar and using language that the public can readily understand" (The Resilience Network 1997: 6; italics in original). But a marketing orientation challenges us to consider not just concepts and language that can be easily understood, but also to identify vehicles that are tailored to most effectively reach each target audience. An on-line journal may not be the most effective marketing vehicle for attracting the attention of the public or of corporate executives, although it may be highly effective at maintaining and feeding an established relationship, particularly within the scientific community. Thus, scientists need to develop more comprehensive marketing campaigns and communication vehicles that can effectively reach important stakeholders who are outside our traditional academic realm (e.g., policy makers, journalists, corporate executives, and the public).

\section{ENVIRO-MARKETERS: WHO'S OUT THERE MARKETING SUSTAINABILITY? WHAT CAN WE LEARN FROM THEM?}

Environmental marketers recognize that people (consumers, corporate actors, and policy makers) do not simply enact behavior based on accessible information. Attitudes, feelings, and beliefs about behavioral control all influence consumer and corporate action. Consequently, educational efforts cannot, by themselves, be expected to make behavior sustainable because they only impact awareness. Education will not necessarily change attitudes, feelings, or behavioral control. Instead, marketing efforts that identify and capitalize on behavioral levers stand the best chance of success (Andreasen 1995).

Although are there are a growing numbers of not-for-profit organizations that are attempting to promote sustainability, I would like to highlight two interesting examples: The Earth Communications Office (ECO) in the United States and Adbusters in Canada. 
The Earth Communications Office (ECO) is a nonprofit organization based in Hollywood that attempts to harness the power of the entertainment and communications industry for environmental goals. ECO's stated mission is to "use the power of communication to improve the global environment" http://www. OneEarth.org. For over eight years, ECO has designed and executed award-winning public service announcements (PSAs) that have been shown in movie theaters, TV, and radio. ECO's ads have been viewed by nearly one billion people worldwide. By offering extremely high-quality advertisements and using well-known actors like Pierce Brosnan, Linda Hunt, and Patrick Stewart (Captain Picard of Star Trek), ECO has been able to receive donated media space. ECO's marketing campaigns are financially supported by a variety of foundations and individuals. Furthermore, ECO undertakes extensive market research in order to demonstrate the effectiveness of its communications.

ECO's previous campaigns focus on a variety of environmental topics (note: ECO's ads are currently being digitized and will shortly be available for viewing on their website: http://www. OneEarth.org):

"Water Planet" is a 30-s spot reminding the audience that water sustains life and must be protected.

"Speak" (30 s) focuses on the damaged state of the world's oceans and marine mammals.

"Hidden City" focuses on the vulnerability of the earth's coral reefs. It has aired in both a 2-min and a 30-s format.

"Mother" ( $2 \mathrm{~min}$ ) presents the view that the Earth must be taken care of if we want it to remain our caretaker and provider.

"Power of One" (2 min) highlights how one person can make a difference. It challenges the audience to act now.

"Connections" ( $2 \mathrm{~min}$ ), based on the words of Chief Seattle, communicates the connections between people around the world as they live within damaged environments.

"Island Home" (30 s) addresses the impact of overconsumption on our island called earth.

ECO's newest (1998) campaign, "Think More. Use Less," focuses on marketing sustainable consumption. The marketing campaign developed print, TV, and cinema for both the United States and Canada. It is currently being translated into eight languages for international distribution. To date, "Think More. Use Less" has played on over 8000 movie screens, with release for cable and television in February 1999. ECO is currently producing an advertising campaign, scheduled for release in September 1999, on global warming. In general, all of ECO's ads convey emotionally appealing messages in high-quality production.

Adbusters, a grassroots Canadian "culture-jamming" media group, has a related, but more radical approach: "The mission of our non-profit society is to redirect our existing commercial media culture towards ecological and social awareness. We feel that our planet cannot survive the existing onslaught of mass media that constantly urges us to consume ever more. We want to create a new media culture, one that does not have commercialism as its heart and soul. To this end, the Media Foundation has created Adbusters magazine, the Adbusters website, and the Powershift Advocacy Agency."

In keeping with this mission, Adbusters has designed a series of low-cost ads that attempt to counter consumer culture and promote more sustainable living. The media group actively utilizes media professionals to develop what they call "uncommercials" http://www.adbusters.org/uncommercials/ [2]. For example, the 30-s uncommercial entitled "Autosaurus" was designed by Adbusters and Greenpeace to promote less automobile use http://www.adbusters.org/uncommercials/auto.html. Adbusters uses many disgruntled advertising professionals and uses a mix of purchased media and public service announcements (PSAs) wherever possible. Adbusters also promotes a step-by-step guide for environmental activists on how to air an uncommercial http://www. adbusters.org/uncommercials/airtime.html.

Like any strategic marketer, both ECO and Adbusters attempt to communicate messages using creative executions that speak to both the hearts and minds of their audiences. Their ads are not simply educational: they recognize the power of emotional imagery. In addition, the ads convey a desired change in behavior: drive less, consume less, act more responsibly, and respect the earth as our home. Although the approaches and creative tone used by ECO and Adbusters may (or may not) be appropriate for the scientific community, their marketing forays can still act as inspirations.

\section{MARKETING ADAPTIVE MANAGEMENT: A CALL TO ACTION}

Organizations like ECO or Adbusters do not promote scientific solutions; that is not their objective. However, this perspective argues that this should be part of the objective of the scientific community. We need to act as a credible scientific voice promoting specific sustainable behavior through approaches such as adaptive management. 
However, a prudent approach would be to first identify a pilot project where we could test out the value of marketing to disseminate important scientific information. Consequently, I suggest that we consider and discuss the following next steps:

Should we establish a marketing steering committee within the broad scientific community?

How do we establish relationships with environmental marketing groups such as ECO? This may be particularly useful, because ECO has already identified coral reefs and global warming as priority areas. As academics, how can we develop useful ties with external marketing practitioners and advertising experts?

What scientific focus could we identify as a good marketing test case? Can we design a marketing campaign that effectively communicates a science-based message?

When can we test it out? How will we measure our impact?

How do we access foundation support for environmental marketing activities? Can we include marketing budgets in our requests for research support?

\section{CONCLUSION}

There is a common misconception that marketing is the tool of the snake-oil salesman, that it is used to make weak messages credible. Or that it smacks of crash commercialism. In some cases, this is undoubtedly true. But the persuasive ability of marketing as a technology does not necessarily limit itself to these applications. If marketing can turn "lead into gold," then it has the potential to make strong science-based messages even more appealing.

In closing, I want to stress that, as scientists and researchers, we don't have to be experts at everything. Not all of us can become (or would want to become) "spin doctors" or marketing managers. But some of us need to, particularly if we wish to re-shape the social landscape and make room for sustainability. To help ensure that our research is effectively delivered, we need to systematically market our collective knowledge and expertise among a variety of target audiences, focusing on those who will continue to have significant impact on the earth's ecosystems.

\section{Endnotes}

[1] Environmental nongovernmental organizations (ENGOs) retaliated to such corporate spins primarily with public relations and web-based internet marketing campaigns, e.g., http://www.foe.co.uk/climatechange/economic. htm or http://archive.abcnews.go.com/sections/us/global_coast1008/index.html.

[2] However, these "uncommercials" can be viewed as too radical for media placement and have been systematically rejected by many networks. In retaliation, Adbusters has launched a series of lawsuits to secure their right to advertise.

\section{RESPONSES TO THIS ARTICLE}

Responses to this article are invited. If accepted for publication, your response will be hyperlinked to the article. To submit a comment, follow this link. To read comments already accepted, follow this link.

\section{Acknowledgments:}

I would like to thank C. S. Holling, John Pastor, Steve Light, Barry Cowell, and two anonymous reviewers for their comments and suggestions. In addition, I would like to thank Kit Thomas and Cassie Gruenstein of the Earth Communications Office (ECO) for their valuable support and help.

\section{LITERATURE CITED}

Andreasen, A. 1995. Marketing social change: changing behavior to promote health, social development, and the environment. Jossey-Bass Publishers, San Francisco, California, USA.

Chapin, F. S., and G. Whiteman. 1998. Sustainable development of the boreal forest: interaction of ecological, social, and business feedbacks. Conservation Ecology 2(2): 12. [online] URL: http://www.consecol.org/vol2/iss2 lart12 
Kotler, P., and Gary Armstrong. 1995. Principles of marketing. Sixth edition. Prentice-Hall, Englewood Cliffs, New Jersey, USA.

Kotler, P., and E. R. Turner.1993. Marketing management analysis, planning, implementation, and control, Cdn. Seventh edition. Prentice Hall, Scarborough, Canada.

Leiss, W., S. Kline, and S. Jhally. 1990. Social communication in advertising: persons, products, and images of well-being. Nelson, Scarborough, Canada.

The Resilience Network. 1997. Draft Case Statement of Science and Policy Partnership for Sustainability (March). C. S. Holling et al. [online] URL: http://www.consecol.org/Journal/editorial/spps...html

\section{Address of Correspondent:}

Gail Whiteman

The North-South Institute; 55 Murray St., Suite 200, Ottawa,

ON, Canada. K1N $5 \mathrm{M} 3$

Phone: 613-241-3535 ext. 249

Fax: 613-241-7435

whiteman@nsi-ins.ca

*The copyright to this article passed from the Ecological Society of America to the Resilience Alliance on 1 January 2000. 